\title{
3d Printing Trends in Building and Construction Industry
}

Prachi Mehar;, Prachi Khobragade, Monika Mendhe, Shitalkaur Bhada, Vibha Singh, Mrs. P. Salodkar

Department of Civil Engineering, Nagpur Institute of Technology, Nagpur, Maharashtra, India

\begin{abstract}
Technological changes have remarkable effect on today's business world that triggers industriesn to re-establish the assembly systems. 3D printing has advanced with the new innovative improvements in added substance producing in the course of the most recent three decades. 3D printing innovations empower structure streamlining and have preferences over ordinary creation techniques. All industries should adopt the new era so as to survive in a very rapidly changing competitive environment. the development industry is additionally under technological developments' pressure to vary. Therefore, 3D printing technology is under a good attention in housing industry as a replacement strategic challenge. the development industry takes 3D printing as a concept of a replacement building technology. The main aim of this paper is to review the 3D printing technology applications of other industries, to review 3D printing attempts in housing industry and to discuss possible application areas for 3D printing intentions in housing industry. This project summarizes the 3Dprinting applications utilized in industries, with a spotlight on adaption strategies in housing industry. Significant writing databases are investigated about 3D printing looks into and furthermore the preliminaries of usage in lodging industry. Collected data is interpreted within the construction research jargon. The conceivable execution territories in development are proposed for future improvements. The paper leads to identifying and classifying the new developments in 3D printing technology in various industries and making projections on the possible adaptation areas in housing industry.
\end{abstract}

Keywords: 3d Printing, Concrete, Time, New Innovative Improvement.

\section{INTRODUCTION}

$3 \mathrm{D}$ solid printing is an inventive development technique that vows to be exceptionally invaluable inside the development field regarding improving development time, cost, plan adaptability, blunder decrease, and natural angles. Concrete is extruded through a nozzle to create structural components layer-by-layer without the employment of formwork or any subsequent vibration. The contribution of this study is to spot and resolve the varied design and operational constraints of $3 \mathrm{D}$ concrete printing, which are of important importance for future development of this construction technique. This paper introduces the topic in two unique stages: structuring the machine on one hand, and planning the solid blend to be utilized on the inverse. Experimental results are presented concerning the combo design and therefore the tests performed to work out the fresh and hardened concrete properties. thanks to the scarcity of published studies on concrete properties utilized in 3D printing, the results could be invaluable to the long run of this technology. The examination may fit become the outline for future 
greater scale ventures like making entire structures utilizing 3D solid printers. 3D Concrete printing might be a development technique that has the capability of manufacturing a predesigned constructing component in 2D layers on each other, the repetition of which completes a 3D model.

3D printing building technology may be a new construction technique started with the invention of 3D printer. Most recent advancements were depicted during this paper with highlighting Contour Crafting as a promising strategy which will have the option to upset lodging industry in not so distant future. it's many advantages of this technology, like reduction of the prices and time, minimizing the pollution of environment and reduce of injuries and fatalities on construction sites may be listed. Combination of Building Information Modeling with the 3D printing building procedure are referenced contrasted and the standard development systems. although many advantages and benefits of this new technology, in fact we've got some concerns are summarized within the conclusions because the technology still has many limitations.

\section{OBJECTIVE}

This paper objective is on the materials aspect through developing the concrete mix to be used during this technology. Several tests were conducted to search out the optimal concrete mix for this function. It also studies the printing mechanism of the 3D machine and proposes an acceptable design for the printer. A structural specimen is printed as a signal of concept for the printing technique. The outcomes of this research and its applications to reallife construction practices target the requirement for improved automation in applied science projects, the requirement for efficiency in resource management and a rapid and less expensive construction method.
The main aim of this paper is to guage the feasibility of concrete for 3D printing and emphasis the impact of this new technology for future prospects. the lack of research on the 3D printing part of cement has driven me to survey the conduct of cement during this zone. The research aims to encourage the employment of concrete in 3D printing thereby reducing costs of construction and increase the speed of productivity within the housing industry.

\section{CURRENT CHALLENGES TO BE OVERCOME INCLUDE}

- Costlier than ordinary development in light of significant expense of 3D printer and absence of recognition inside the business with $3 \mathrm{D}$ printing advancements and applications.

- Currently a limited number of materials are used, although experimentation is underway with printers capable of using multiple materials to provide more complex assemblies.

- 3D printers will be large and, therefore, difficult and expensive to position on site.

- 3D printing acquires more straightforward expenses to make the advanced model which will prompt safe, financially savvy items.

- 3D Printers are at present moderate contrasted with standard development, in spite of the fact that they'll be worked 24 hours every day, seven days of the week.

- The potential of a disruptive impact on the kind of skills and labor needed to style and build homes.

\section{THE FUTURE OF 3D PRINTING IN RESIDENTIAL CONSTRUCTION}

There is a large range of views about where the technology may well be headed. Although 3D printing remains in its time period all told industries, the potential benefits seem to be driving the 
technology forward. Some recommend 3D printers will be utilized chiefly to print building segments and boards either in processing plants or on location, while others imagine $3 \mathrm{D}$ printing as a transformative technology that might revolutionize the development industry.

\section{D PRINTING OF BUILDINGS FOR CONSTRUCTION OF THE SUSTAINABLE HOUSES}

$3 \mathrm{D}$ printing technology to use building are going to be increase sustainability. Houses can built supported the fabric life cycle, which will be utilized in evaluating the environmental sustainability of building materials. Creating the buildings with complicated shapes, may become one in all the largest advantages for many architects. Their imagination are going to be able to defeat previous obstacles associated with limitation of traditional techniques of building.

\section{TESTING PROCEDURES}

The choice of the optimal mix necessitates several tests to be conducted, keeping in mind the target parameters to be achieved mentioned in Section2. These factors together contribute in equal importance to the writing. Firstly, preliminary trial tests are done that focus on extrudability, a critical parameter that ensures the right printing out of the nozzle. this is often primarily tormented by the quantities and distributions of the dry constituents within the mix. to see the starting mix proportions, the concept of slip-form concrete design, which contains a selfcompacting property and doesn't require further consolidation, was followed. Once the obtained paste is found extrudable, several tests were performed to fulfill the opposite requirements.

The quantities of additives then start to play the prominent role. Below may be a description of the tests performed to confirm following target criteria are met:
- Extrudability: It refers to the capacity of the concrete to be extruded out of the nozzle.Also, the printed paste should be beyond cracks and separations.

- Compressive strength: The target strength of the concrete is set using BS 1881-116:1983 and 5x5 concrete cubes. Strength is especially important since what's printed is that the structure in layers instead of its entirety without delay. Since setting time should be assumed to be instantaneous, and since the printing happens only in a very matter of minutes, the target strength and strength gain should be high.

- Flow ability: Measurement of flow ability is achieved by performing the slump flow test. The concrete is detached of an inverted cone. The time required for the combo to spread by a selected diameter is measured and also the rate of flowing can subsequently be obtained. An An easily expanding mix corresponds to a greater flowability and workability. Buildability: this is often measured by the amount of layers of the printing specimen which will be achieved without collapse. The target average number of layers is 5 .

- Open Time: This criterion is very important the standard method. within the latter, the initial and final setting times are more representative but don't have much relevance in concrete printing representation of the concrete workability change with time. it's calculated using the slump flow test to induce the flow ability over specific 3D Concrete Printing presents itself as a promising tool within the housing industry. With a combination that satisfies various design and operational constraints, houses are often built using this innovative technique without the utilization of formwork. 3D concrete printing offers savings in terms of long-term cost, time, labor and complexity, which are vital current factors 
within the housing industry. Furthermore, it's less harmful to the environment than more traditional construction methods. Additionally to being a promising tool to engineers in terms of structural design, 3D concrete printing is additionally a possible tool for architects in architectural design. As the method is not limited by any type of formwork or manual labor, designers will have much more design flexibility in that scope.

\section{D PRINTED OFFICE IN DUBAI}

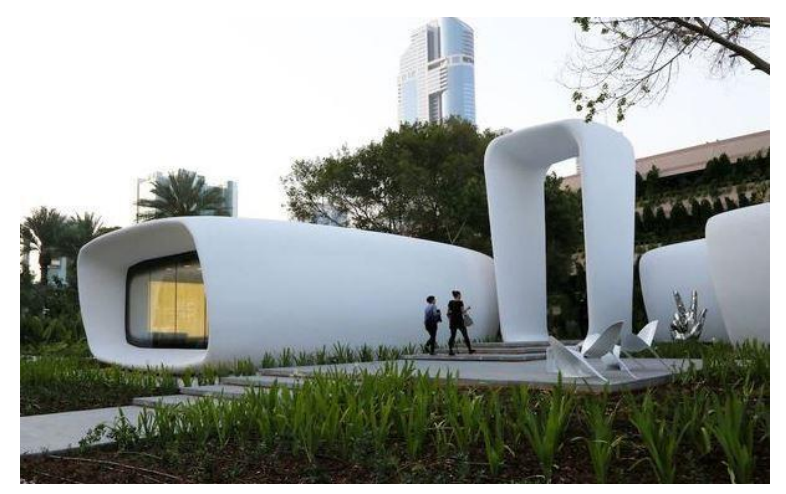

Fig $1: 3 \mathrm{D}$ concrete printed office in Dubai, UAE

3D printing concrete has end up being solid and natural inviting in the examination forms. Nonetheless, there are different parts of solid that need improvement for the procedure to be acknowledged worldwide and utilized on a mass scale. A few examines are continuous in different specialized establishments and colleges to adjust 3D printing concrete in the development procedure and increment computerization in the development business. In barely any years later 3D printing solid will be utilized comprehensively to decrease squander in the development procedure and fabricate solid structures productively. In the segments beneath, a portion of the territories where $3 \mathrm{D}$ printed cement could be utilized are talked about quickly.

\section{CONCLUSION}

The 3D printing technology has rapidly changed the views on using concrete as a $3 \mathrm{D}$ printable material alone. The rising populations have created housing chaos in the middle and low class families in the housing sector. Only the rich and the powerful can spend on housing that can have complete freedom in design and execution of the project. 3D printing concrete can possibly support the center and lower class families have a house with their modified plan that is more affordable to assemble and earth well disposed. The lack of interest in this field of $3 \mathrm{D}$ printing concrete has made me focus on this particular technology. This thesis begins with an introduction to the various $3 \mathrm{D}$ printing technologies that have been practice with different materials such as plastic, metal and powdered materials.

The following sections focuses on the use of concrete as a 3D printing material. The requirements and challenges in adopting concrete to 3D print have been discussed. The types of $3 \mathrm{D}$ printing concrete technologies and the research and commercial projects that have practiced the technologies have been listed. And the various possibilities of using concrete as a $3 \mathrm{D}$ printable material and future of this technology has been analyzed. There are several possibilities for this technology to develop and move into commercial markets. Be that as it may, the innovation needs more assets to grow quicker. The cooperation with the academia needs to be improved. Many Universities have been involved in research on finding the suitable proportions of raw materials used and the inclusion of recycled building materials for the 3DCP technology.

Cooperation with conventional suppliers needs to be improved and there have been many signs of interest from larger construction companies towards this technology. Some of the companies that have invested in development of own 3D construction printing technologies are Skanska from Sweden, Sika from Switzerland and Bougues from France. 
Companies that have invested in new 3D construction printing startups are Vinci from France, Doka from Austria and Caterpillar in the USA. The truth behind the $3 \mathrm{D}$ construction printing projects is that none of the completed projects have been competitive so far. There might have been some saving in labour costs and materials, but overall it has not been competitive to the traditional methods of construction. It is evident that many companies and academia is interested in the 3D concrete printing technology but there is a lot to be learned on this subject in the near future. It is difficult to obtain good results and be efficient the first time. The technology has proven its potential and will become competitive if the resources are continued to be applied. The phase of scientifical advancement in technology has risen in the past few decades from mobile phones to artificial intelligence. So the future holds great guarantees for 3D Concrete Printing. A view into market matureness shows that it would be only a matter of time the trend in the construction field changes. The market prices for this technology are very high at the moment because of the less popularity of this technology. Later on the opposition inside contractual workers will increment because of interest in less expensive lodging and the market turns out to be consistent and progressively develops the 3D solid printing industry.

\section{REFERENCES}

[1]. Bos, F. et al. (2016) 'Additive manufacturing of concrete in construction: potentials and challenges of 3D concrete printing', Virtual and Physical Prototyping. Taylor \& Francis, 11(3), pp. 209-225. doi: 10.1080/17452759.2016.1209867.

[2]. Chang, S. H. (Shawn H. (2016) 'Exploring the evolution of additive manufacturing industry : a study of stakeholder requirements and architectural analysis of Desktop three- dimensional printing Segment'. Massachusetts Institute of Technology. Available at: https://dspace.mit.edu/handle/1721.1/106243 (Accessed: 15 January 2018).

[3]. Chen, D. et al. (2015) 'Direct digital manufacturing: definition, evolution, and sustainability implications', Journal of Cleaner Production. Elsevier, 107, pp. 615-625. doi: 10.1016/J.JCLEPRO.2015.05.009.

[4]. Dana Goldberg (no date) History of 3D Printing: It's Older Than You Think. Available at: https://www.autodesk.com/redshift/history-of3d-printing/ (Accessed: 15 January 2018).

[5]. Elizabeth Palermo (no date a) What is Selective Laser Sintering? Available at: https://www.livescience.com/38862-selectivelaser-sintering.html (Accessed: 24 January 2018).

[6]. Elizabeth Palermo (no date b) What is Stereolithography? | 3D Printing. Available at: https://www.livescience.com/38190-

stereolithography.html (Accessed: 24 January 2018).

[7]. Fused Deposition Modeling: Most Common 3D Printing Method (no date). Available at: https://www.livescience.com/39810-fuseddeposition-modeling.html (Accessed: 24 January 2018).

[8]. John Kosowatz, Senior Editor and ASME.org (2017) Mobility Comes to Large-Scale 3D Printing. Available at: https://www.asme.org/engineeringtopics/articles/manufacturing-design/mobilitycomes-largescale-3d-printing (Accessed: 21 December 2017).

[9]. Julia (no date) 3ders.org - 3D printed concrete office-hotel coming to Copenhagen | 3D Printer News \&amp; 3D Printing News. Available at: https:/www.3ders.org/articles/20170907-3dprinted-concrete-office-hotel-coming-tocopenhagen.html (Accessed: 3 January 2018). 
[10]. Khoshnevis, B. (2004) 'Automated construction by contour crafting-related robotics and information technologies', Automation in Construction. Elsevier, 13(1), pp. 5-19. doi: 10.1016/J.AUTCON.2003.08.012.

Cite this article as : Prachi Mehar, Prachi Khobragade, Monika Mendhe, Shitalkaur Bhada, Vibha Singh, Mrs. P. Salodkar, "3d Printing Trends in Building and Construction Industry", International Journal of Scientific Research in Science and Technology (IJSRST), Online ISSN : 2395-602X, Print ISSN : 23956011, Volume 7 Issue 3, pp. 314-319, May-June 2020. Available at doi : https://doi.org/10.32628/IJSRST207342 Journal URL : http://ijsrst.com/IJSRST207342 